\title{
Party nomination strategies in flexible-list systems: Do preference votes matter for realistic list positions?
}

Accepted for publication in Party Politics

\section{Gert-Jan Put ${ }^{1}$}

Senior Researcher KU Leuven, Research Center for Regional Economics

\section{Jef Smulders}

Research Fellow KU Leuven, Public Governance Institute

\section{Bart Maddens}

Professor of Political Science KU Leuven, Public Governance Institute 


\begin{abstract}
Previous studies on flexible-list systems demonstrate that party selectorates promote candidates with a high number of preference votes to better list positions in the next election. This research note asks whether these rank promotions are limited to candidates in unrealistic list positions at the lower end of the ballot, or also include candidates moving into realistic list positions (i.e. electorally safer highest ranks). Using a longitudinal dataset of candidates for eighteen parliamentary elections in Flanders (Belgium), we first successfully replicate the earlier established preference vote-effect on future list positions, but subsequently show that promotions from unrealistic to realistic positions are relatively rare. Moreover, preference votes do not seem to affect the ability to move upwards on the list or to receive a realistic position at the next election when controlling for incumbency and list position at the previous election. Robustness tests using different operationalizations for realistic position lead to similar empirical results. Preference votes do not seem to matter for realistic list positions.
\end{abstract}

Key words: flexible-list systems, nomination strategies, Belgium 


\section{Introduction}

Although relatively widespread among European democracies, scholars have labeled flexiblelist PR as a not well understood and notoriously difficult electoral system which is hard to categorize into existing taxonomies (Däubler and Hix, 2018). Arguably the most peculiar trait of this hybrid system is the paradox that candidates build personal reputations and engage in personal vote-seeking behavior while preference votes generally do not determine whether they get elected. Instead, the difference between election and defeat depends almost entirely on the party-provided rank order of candidates on the ballot list (Shugart, 2005).

Recently, empirical studies on how electoral results shape the internal organization of political parties shed more light on this puzzle and improved our understanding of candidate behavior in list PR systems. Parties use their candidates' preference-vote tallies to decide on political promotions (Folke et al., 2016; Meriläinen and Tukiainen, 2018). Specifically with regard to flexible-list systems, Crisp et al. (2013) show that Slovakian parties reward better list positions in future elections to candidates with high preference vote-earning capacity. Building on this work, André et al. (2017) bring evidence that party selectorates in Belgium, Slovakia and Czech Republic are responsive to voters' candidate preferences when drafting candidate lists for the next election.

This research note addresses an important issue which was ignored by previous studies on the flexible-list PR case: do these promotions to better list positions allow returning candidates to transfer from hopeless pre-electoral list ranks, where the chances of getting elected are virtually non-existent, to the electorally safer highest ranks? Rank promotions based on electoral performance are only 'meaningful' if candidates get access to the highest list ranks at some point. We introduce realistic and unrealistic list positions into the analysis of rank effects and 
show that these meaningful promotions are rare, and do not depend on preference votes in previous elections.

We constructed a dataset of 1,084 candidates running in two consecutive federal or regional elections in Flanders (Belgium) between 1987 and 2014. For each candidate who ran in two elections e and e+1 for the same parliament, we collected data on list position, preference votes and incumbency status, which were included in the analysis by André et al. (2017), and in addition we registered candidates' gender, age, number of prior candidacies and local office status. While these traits were not taken into account in previous work, the vast literature on political recruitment argues that they shape the nomination strategies of party selectorates as well (e.g. Krook, 2010; Stockemer and Sundström, 2018; Chiru and Popescu, 2017; Shugart et al. 2005).

We start the empirical section with a replication of the final OLS regression in Andre et al. (2017, Table 4), extended by bringing into the model these additional candidate traits. Our analysis arrives at results similar to the original study, and therefore strengthens confidence that the earlier established preference vote-effect on future list ranks is not a spurious effect, caused by other candidate traits that are known to affect list positions and preference votes. We then develop the analysis further by looking at list promotions while taking into account realistic versus unrealistic sections of the list, which is operationalized in four different ways to check the robustness of our findings. We find that only a very limited group of candidates $(7.6 \%)$ received a 'meaningful' promotion from an unrealistic to a realistic position.

Subsequently, a multinomial logit model with the trichotomous response variable 'Lower Rank - Same Rank - Higher Rank' shows that preference votes do not affect the ability to move upwards on the ballot list when controlling for incumbency and realistic list positions at the previous election. Finally, a binomial logit model juxtaposing returning candidates in 
unrealistic and realistic list positions at election e+1 confirms that electorally popular candidates in the previous election are not granted access to the safest list ranks, regardless of the chosen operationalization. Even a subsample analysis limited to candidates in unrealistic positions at election e does not bring consistent support that electoral performance in the previous election makes a difference in terms of realistic positions.

Although our replication exercise confirms the 'preference vote to list position' finding for flexible-list systems, we also shed an important new light on this mechanism: the responsiveness of party selectorates to voters' candidate preferences seems to be limited to lower ranked candidates on the list. Meaningful promotions do not take place very often, and for those rare candidates who succeed in moving from unrealistic to realistic positions, preference votes do not even matter.

\section{Meaningful candidate promotions: access to realistic list positions}

In their original cross-national study on flexible-list systems, André et al. (2017) acknowledge that "for positions near the top of the list, the results indicate, party selectorates are not as responsive to voters' preferences as other considerations enter their deliberation [...]". In this research note, we take this point further and argue that access to realistic list positions is almost exclusively reserved for incumbents seeking re-election.

Party selectorates estimate the costs and benefits of re-selecting incumbents for the next election. Some of the obvious benefits are their electoral appeal and legislative experience. Incumbent MPs can also get de-selected or relegated to lower list positions as a result of dissident behavior or causing damage to the image of party cohesion. In practice, however, incumbent de-selection will only rarely take place. The trade-off between incumbency 
advantage and dissent fits the line of reasoning presented by Crisp et al. (2013): party selectors place incumbents with strong personal reputations in high list ranks, at the price of party cohesion. Therefore, we expect that promotions to better list ranks and changes up and down the list more generally are limited to those sections of the ballot list where no incumbents are to be found: non-winnable positions at the lower end of the ballot list.

To investigate this empirically, we distinguish realistic and unrealistic list positions on party lists. Realistic list positions refer to positions from which candidates are highly likely to win a seat. Hennl and Kaiser (2008) show that parties pre-estimate secure list positions based on previous electoral results and survey data. Alternative operationalization approaches from the literature include looking at which exact list positions led to election throughout several previous election results (Stoffel and Sieberer, 2018). However, the latter option requires crosstemporal stability in parliament's size, district magnitude and ballot list length.

Our operationalization scheme takes into account party magnitude P (i.e. the number of seats for the party-in-district in the previous election) and district magnitude M. More specifically, the first $\mathrm{P}$ positions on the candidate list are considered realistic. Additional realistic positions are added immediately after the highest ranked realistic position to account for electoral gains according to the following rules:

$$
\begin{aligned}
& \text { if } M>=10 \text { and } P>=5:+2 \text { realistic positions } \\
& \text { if } M<10 \text { and } P<5:+0 \text { realistic positions } \\
& \text { in all other scenarios: }+1 \text { realistic position }
\end{aligned}
$$

This operationalization scheme has already been applied in earlier work (Put and Maddens, 2013). Nevertheless, in order to test the robustness of our findings we also present models (in 
the online supplemental material) with alternative operationalisations, narrowing the range of realistic positions on the list. The first alternative registers party magnitude $\mathrm{P}$ in the previous election and considers the first $\mathrm{P}$ positions on the list as realistic, the second approach applies the more strict $\mathrm{P}-1$ rule on the top list positions, and the final approach limits realistic positions to the P-2 highest ranked candidates.

\section{Data on Flemish candidates for parliamentary elections (1987-2014)}

We collected biographical and preference voting data on candidates of Flemish political parties running for eighteen federal and regional elections in Belgium between 1987 and 2014. Our dataset comprises eight federal Lower House elections, five federal Senate elections and five regional elections (Flemish Parliament). As the analysis takes into account vote-earning capacity and list position in the previous election, we checked which candidates ran in two consecutive elections for the same parliament, leading to an original dataset including 1,084 observations. $^{2}$

This dataset comprises returning candidates running for seven Flemish parties: Socialists (SP/sp.a), Liberals (PVV/VLD/Open Vld), Christian-Democrats (CVP/CD\&V), Greens (Agalev/Groen), Flemish Nationalists (VU/N-VA), Far Right (Vlaams Blok/Vlaams Belang) and Right-Liberals (LDD). The online supplemental material presents the number of candidates

\footnotetext{
${ }^{2}$ So-called 'list pushers' - i.e. candidates running from the very last position on the ballot - were excluded from the analysis for substantial reasons. Belgian parties have a tradition of nominating prominent and senior politicians for highly visible final list positions (Van Erkel, 2017), which is not in line with the general idea that higher implies better on the ballot list.
} 
per set of consecutive elections retained for the analyses. ${ }^{3}$ Throughout the time period under study, several contextual changes have taken place which render the comparability of candidates in two consecutive elections impossible.

First, two electoral district reforms led to a significant increase in district magnitude. As part of the fourth Belgian state reform in 1993, the smallest districts for the Lower House elections were merged. Since 2002, these elections are organized over large districts that coincide with Belgian provinces. Second, some of the Flemish parties formed electoral alliances and submitted joint candidate lists for several elections under study. Specifically, the ChristianDemocrats joined forces with the Flemish Nationalists for the 2004 regional and 2007 federal elections. Moreover, in the same elections and also in 2003 the Flemish Socialist Party constituted an electoral alliance with a smaller partner named Spirit. Third and finally, the Belgian Lower House has decreased in size. In 1995 the number of parliamentary seats was lowered from 212 to 150 , which affected DM and the number of list positions. ${ }^{4}$ Therefore, returning candidates running in any of these sets of incomparable consecutive elections are left out of the analysis.

\section{Empirical analysis}

\footnotetext{
${ }^{3}$ Candidates who switched parties or districts were left out of the analysis. In Belgium, separate lists of successor candidates are presented to voters at the voting booth. When an elected MP does not take up the seat, becomes a minister, resigns or leaves the seat vacant due to illness or death, a successor candidate will be assigned to take up this seat according to rank order and preference votes. As the list position of a successor candidate who runs as an 'effective' candidate in the next election cannot be compared, we exclude these successor candidates.

${ }^{4}$ The number of effective candidates on a ballot list equals the number of seats in the district.
} 
The empirical section of this research note extends the analysis of André et al. (2017) in three ways: (A) by replicating their final OLS regression and bringing new candidate traits into the model; (B) by showing that candidate promotions to better list positions are limited to the lower ranked positions on the ballot list; and (C) by showing that access to realistic positions in the next election is not affected by preference votes in the previous election.

\section{A. Replication of André et al. (2017) model with additional candidate traits}

In what follows, we replicate André et al. (2017) and bring the mentioned four new candidatelevel variables into the model. Gender (1: female; 0 : male) and local roots (1: holding local office $^{5}$; 0: not holding local office) are included as binary independent variables, age is continuous and electoral experience counts the number of prior candidacies. ${ }^{6}$ The possibility of having a large number of prior candidacies is higher in the most recent elections. Experience is therefore recoded into a categorical variable to make experience levels more comparable across observations over time (1: second candidacy, which is the minimum in this research design; 2 : third candidacy; 3: at least fourth candidacy). These four additional traits are measured at election e+1. We include election year and party fixed effects to remove unobserved heterogeneity in our data. Moreover, we cluster standard errors by party list in each election, as the error terms for candidates on the same ballot list will be correlated: the ballot position of one candidate in a particular district affects positions of co-partisans on the same list.

Our modelling and operationalization strategies mimic André et al. (2017): the dependent variable is the candidate's list position at election $\mathrm{e}+1$, for which we take the decimal logarithm to control for the fact that candidates take up a wider range of list positions in large districts

\footnotetext{
${ }^{5}$ This outcome comprises the office of mayor, alderman and local councilor.

${ }^{6}$ To take into account prior candidacies of those candidates running during the first elections included in the analysis, we checked whether they were also present on ballot lists in two earlier federal elections (1985 and 1981).
} 
compared with candidates in small districts. The vote-earning capacity of candidates is measured through their rank difference, which subtracts the candidate's intra-list rank based on the number of preference votes from the candidate's rank on the party-determined ballot list. As a result, positive values indicate that candidates performed more strongly in terms of preference votes than expected. In line with André et al. (2017), the candidate rank in election e and incumbency status are also accounted for in the models.

We start by replicating the final OLS regression model of changes in list position by André et al. (2017, Table 4) for the Flemish data, as presented in Model I in Table 1. Negative parameter estimates indicate that the corresponding variable helps candidates to access higher and better list positions (i.e. lower rank numbers), positive estimates imply higher and thus less attractive list positions (i.e. higher rank numbers). The replication is successful: our results confirm that the preference votes which candidates receive in an election, as measured by rank difference, predict the future list position, even when controlling for incumbency status of returning candidates.

Table 1: OLS models of changes in list position over consecutive elections.

\begin{tabular}{lcc}
\hline & Model I & Model II \\
\hline Rank difference at e & $-0.023^{* * *}$ & $-0.024 * * *$ \\
& $(0.003)$ & $(0.003)$ \\
List position at e & $0.038^{* * *}$ & $0.038^{* * *}$ \\
& $(0.002)$ & $(0.002)$ \\
Incumbent at e+1 & $-0.292^{* * *}$ & $-0.270^{* * *}$ \\
& $(0.025)$ & $(0.025)$ \\
Age at e+1 & & $0.002^{* *}$ \\
& & $(0.001)$ \\
Gender (1=female) & & $0.067 * * *$ \\
& & $(0.018)$ \\
Local office at e+1 & -0.003 \\
Electoral experience at e+1 (ref.: $2^{\text {nd }}$ & $(0.018)$ \\
candidacy) & & \\
Third candidacy & & 0.012 \\
At least fourth candidacy & & $(0.021)$ \\
\hline
\end{tabular}




\begin{tabular}{lcc}
\hline & & $(0.02)$ \\
Party fixed effects & Included & Included \\
Election year fixed effects & Included & Included \\
Constant & $0.394 * * *$ & $0.268 * * *$ \\
& $(0.035)$ & $(0.052)$ \\
\hline $\mathrm{N}$ & 1,084 & 1,084 \\
$\mathrm{R}^{2}$ & 0.638 & 0.645 \\
Note: Standard errors are shown in parentheses and clustered by party list in each election. The dependent variable is \\
the logarithm of a candidate's list position at $\mathrm{e}+1 .{ }^{*} \mathrm{p}<0.05,{ }^{* *} \mathrm{p}<0.01,{ }^{* * *} \mathrm{p}<0.001$.
\end{tabular}

Model II shows the results when including the four additional candidate traits. Local office and electoral experience do not affect future list positions. Candidate age has a small but statistically significant effect on list position, in the sense that older candidates generally get lower positions than younger candidates. The age effect can either point to a more critical evaluation of older vis-à-vis younger candidates by selectorates, or a stronger inclination of older candidates to run from lower positions to support their party. As regards gender, Model II suggests that, compared to male counterparts, female candidates are assigned to lower list positions in subsequent elections. In sum, although the model shows that age and gender does affect list placement, adding these four additional traits does not change the previously established link between preference votes and future list positions.

\section{B. Modelling changes in list positions}

We now introduce realistic positions into the analysis and examine whether rank promotions also include candidates moving from the unrealistic to the realistic section of the list. We find that only 82 out of 1,084 returning candidates between 1987 and 2014 or $7.6 \%$ of the observations in our dataset experienced these meaningful promotions. ${ }^{7}$ Recall that our research design is focusing on returning candidates, which inflates the number of meaningful

\footnotetext{
${ }^{7}$ The exact share of meaningful promotions depends on the operationalization of realistic positions, and ranges between 7 and 17\% (see Online supplemental material III).
} 
promotions as candidates who are unlikely to be promoted are less inclined to return to run for election altogether.

The large majority of changes in list positions take place at lower list ranks, from one unrealistic position to another. This implies that returning candidates who were in realistic list positions at election e undergo far less positional changes. The histograms of changes in list positions between election e and e+1 as shown in Figure 1 confirm these expectations: amongst candidates in unrealistic positions (left), the variation in list changes over consecutive elections is considerably higher than amongst candidates in realistic positions (right). More specifically, $76 \%$ of all candidates starting from realistic positions either attained the same list position in $\mathrm{e}+1(55.3 \%)$, moved one position forward $(5.8 \%)$ or one position downward (14.9\%).

Figure 1: Histogram of changes in list positions for returning candidates in unrealistic and realistic list positions at election e.

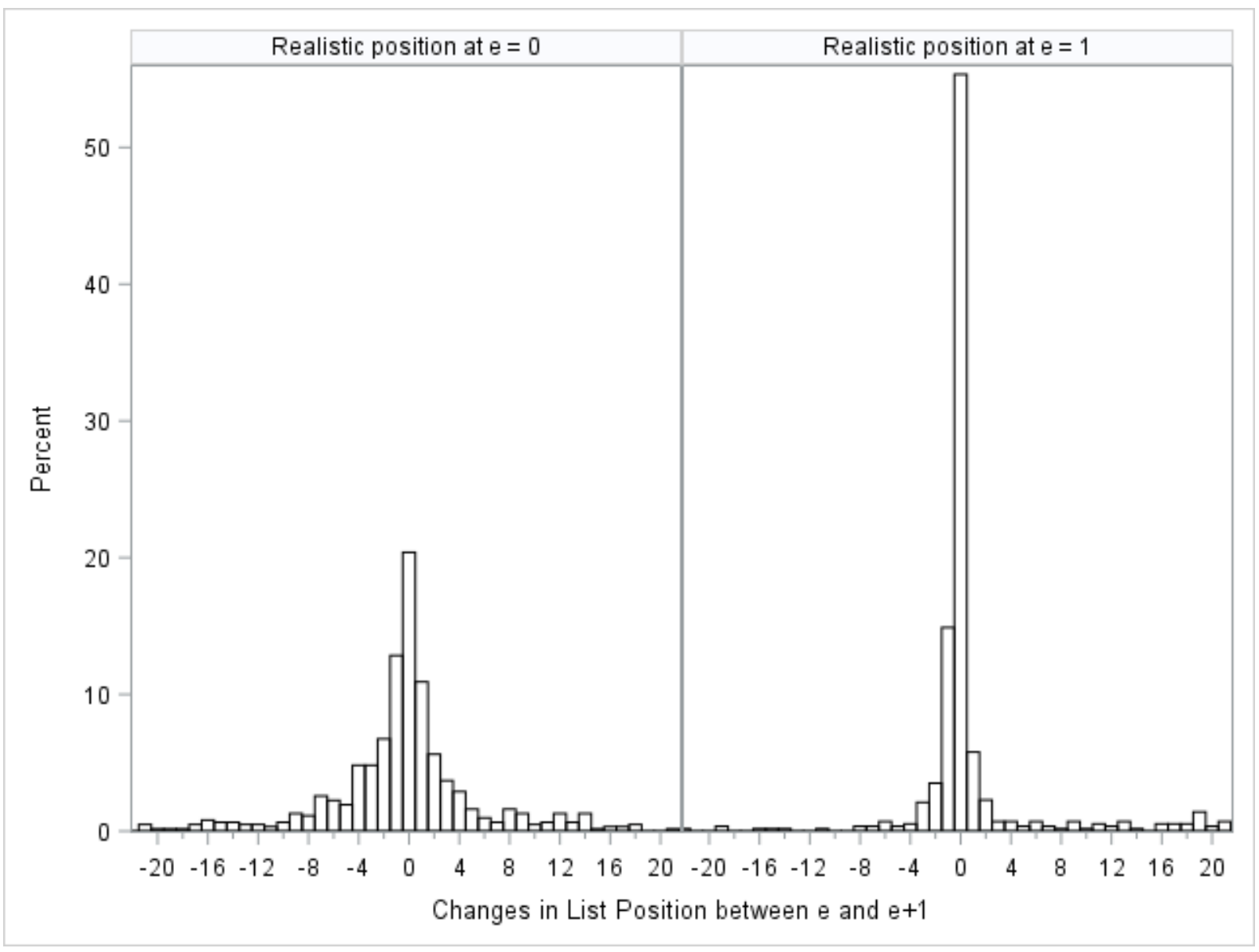


Do preference votes in the previous election help returning candidates to climb to a higher rank, when taking into account incumbency and realistic list positions? We run a multinomial logit model with a trichotomous response variable: lower rank at the next election, same rank (reference category) and higher (better) rank. In contrast with the replication exercise where we analyzed the list position at election e+1, we compare returning candidates' list positions in election e and e+1.

Table 2 indicates that candidates with strong electoral performance in the previous election measured by rank difference - will be less likely to receive lower positions. Promotions to higher ranks, however, are not affected by preference votes at election e: the multinomial logit coefficient for rank difference regarding the response 'Higher Rank' (-0.011) is not significant. The positive coefficient for list position at e implies that candidates in lower positions are being moved around more on the list, either downwards or upwards. Moreover, the negative coefficients for incumbency show that incumbent returning candidates, of which the large majority ran from a realistic list position at election e, are less likely to receive a lower rank. As these candidates are already high on the list at e, the odds of moving even higher are also limited. As a result, they very often end up on identical list positions over consecutive elections. The models with alternative operationalization of realistic positions (Online supplemental material II) yield very similar results.

Table 2: Multinomial logit model of changes in list position over consecutive elections.

\begin{tabular}{lcc}
\hline & Lower Rank & Higher Rank \\
\hline Rank difference at e & $-0.156^{* * *}$ & -0.011 \\
& $(0.037)$ & $(0.030)$ \\
List position at e & $0.069^{*}$ & $0.127^{* * *}$ \\
& $(0.031)$ & $(0.030)$ \\
Realistic position at e & -0.250 & -0.054 \\
& $(0.313)$ & $(0.256)$ \\
Incumbent at e+1 & $-1.222^{* * *}$ & $-0.663^{*}$ \\
& $(0.307)$ & $(0.283)$ \\
Age at e+1 & 0.002 & -0.016 \\
& $(0.011)$ & $(0.010)$ \\
\hline
\end{tabular}




\begin{tabular}{lcc}
\hline Gender $(1=$ female) & 0.154 & 0.222 \\
& $(0.200)$ & $(0.180)$ \\
Local office at e+1 & 0.105 & -0.001 \\
& $(0.221)$ & $(0.195)$ \\
Electoral experience at e+1 (ref.: $2^{\text {nd }}$ & & \\
candidacy) & 0.125 & -0.245 \\
Third candidacy & $(0.253)$ & $(0.245)$ \\
& -0.270 & $-0.713^{* *}$ \\
At least fourth candidacy & $(0.262)$ & $(0.236)$ \\
& Included & Included \\
Party fixed effects & Included & Included \\
Election year fixed effects & -0.965 & 0.579 \\
Constant & $(0.641)$ & $(0.587)$ \\
\hline $\mathrm{N}$ & \multicolumn{2}{c}{0.084} \\
Cox and Snell's $\mathrm{R}^{2}$ & \multicolumn{2}{c}{0.349} \\
\hline
\end{tabular}

Note: Standard errors are shown in parentheses and clustered by party list in each election. The dependent variable is 'changes in list position' with three outcomes: Lower Rank-Same Rank-Higher Rank (Same rank is the reference category). $* \mathrm{p}<0.05, * * \mathrm{p}<0.01, * * * \mathrm{p}<0.001$.

C. Modelling chances of obtaining realistic list positions

In a final step, we use the realistic-unrealistic positions dichotomy as the response variable and examine whether preference votes in election e gives access to realistic positions at e+ 1 . We run binomial logit models juxtaposing realistic positions to unrealistic ones (reference category). We take into account incumbency status and realistic position in election e, as we expect that once we control for these covariates the vote-earning capacity of a candidate will not affect the chances on a realistic position at $\mathrm{e}+1$.

When taking into account the full sample of 1,084 returning candidates (Table 3, first column), we find that access to realistic positions in election $e+1$ is not determined by rank difference. Instead, both incumbency and running from a realistic position at election e have a significant effect. Other candidate traits do not matter, save the age of returning candidates: all other things equal, older candidates have a lower chance of accessing these positions. These results confirm 
that realistic positions are reserved for incumbents and candidates who were granted access to the realistic section of the list in earlier elections.

Table 3: Binomial logit model of realistic versus unrealistic list positions at election e+1.

\begin{tabular}{lcc}
\hline & $\begin{array}{c}\text { Realistic position } \\
\mathbf{e + 1}\end{array}$ & $\begin{array}{c}\text { Realistic position } \\
\mathbf{e + 1}\end{array}$ \\
& Full sample & Subsample \\
\hline Rank difference at e & 0.040 & $0.107^{* *}$ \\
List position at e & $(0.034)$ & $(0.041)$ \\
& $-0.082^{* *}$ & $-0.069^{*}$ \\
Realistic position at e & $(0.031)$ & $(0.033)$ \\
& $1.886^{* * *}$ & - \\
Incumbent at e+1 & $(0.275)$ & \\
& $2.755^{* * *}$ & $2.567^{* * *}$ \\
Age & $(0.305)$ & $(0.436)$ \\
& $-0.047^{* * *}$ & $-0.038^{*}$ \\
Gender (1=female) & $(0.013)$ & $(0.017)$ \\
& -0.242 & -0.106 \\
Local office & $(0.264)$ & $(0.344)$ \\
Electoral experience at e+1 (ref.: $2^{\text {nd }}$ & $0.470^{*}$ & 0.405 \\
candidacy) & $(0.238)$ & $(0.304)$ \\
Third candidacy & & \\
& & \\
At least fourth candidacy & 0.039 & 0.089 \\
Party fixed effects & $(0.287)$ & $(0.369)$ \\
Election year fixed effects & 0.356 & -0.162 \\
Constant & $(0.296)$ & $(0.411)$ \\
& Included & Included \\
N & Included & 0.048 \\
Cox and Snell's R ${ }^{2}$ & 0.827 & $(0.907)$ \\
\hline
\end{tabular}

Note: Standard errors are shown in parentheses and clustered by party list in each election. The dependent variable is 'list position at election $\mathrm{e}+1$ ' with two outcomes: realistic-unrealistic position (unrealistic is the reference category). ${ }^{*} \mathrm{p}<0.05$, ${ }^{* *}$ $\mathrm{p}<0.01, * * * \mathrm{p}<0.001$.

The second model presents an even more strict empirical test of the link between preference votes and meaningful promotions (Table 3, second column). If we only look at those candidates who ran from an unrealistic position in election e, the rank difference of a candidate does increase the odds of getting a realistic position in election e+ 1 . However, this effect is not robust as all three models using an alternative operationalization of realistic positions do not show a 
significant effect of rank difference (see Online supplemental material III). Access to realistic positions is consistently explained by previous list position and incumbency status. Put differently, those candidates who succeeded in getting elected from an unrealistic position in the previous election are granted access to the top list positions in the next election. Candidates with high rank difference scores, however, are not rewarded with realistic positions by party selectorates. Preference votes do not seem to matter for realistic list positions.

\section{Discussion}

This research note presented an important extension to research on the link between preference votes and future list positions in flexible-list PR systems. While we successfully replicated André et al. (2017), we also show that rank promotions are limited to lower ranked candidates and only rarely imply moving towards realistic positions. Moreover, even within the limited group of candidates who transferred from unrealistic to realistic positions over consecutive elections, preference votes do not significantly explain this move. Flemish party selectorates reward better list positions in future elections only to candidates with high preference voteearning capacity in the lower, unimportant sections of the ballot list. Parties' responsiveness to voters' candidate preferences decreases as one moves towards the higher sections of the list.

The lack of promotions from unrealistic to realistic list positions might suggest that party selectorates master the art of creating a perception of voter responsiveness. Indeed, selectors reward a successful lower ranked candidate in the previous election with a better, yet again unrealistic list position in the next election. Electoral candidates are inclined to believe the selectorate's narrative that hard campaign work pays off: rare examples of meaningful promotions for co-partisans might strengthen this perception, and lower ranked candidates see 
that their position on the list is indeed improving. At least in the case of Flanders, however, party leaders still seem to exercise strong ballot control, that is control over ballot positions that matter. Those same leaders can use promotions to higher list positions as a dangling carrot to incite massive campaign efforts by their lower ranked candidates.

\section{References}

André A, Depauw S, Shugart MS and Chytilek R (2017) Party nomination strategies in flexiblelist systems: Do preference votes matter? Party Politics 23(5): 589-600.

Chiru M and Popescu M (2017) The value of legislative versus electoral experience and gender in explaining candidate list placement in closed-list PR. Problems of Post-Communism 64(2): 65-78.

Crisp BF, Olivella S, Malecki M and Sher M (2013) Vote-earning strategies in flexible list systems: Seats at the price of unity. Electoral Studies 32(4): 658-669.

Däubler T and Hix S (2018) Ballot structure, list flexibility and policy representation. Journal of European Public Policy 25(12): 1798-1816.

Folke O, Persson T and Rickne J (2016) The primary effect: Preference votes and political promotions. American Political Science Review 110(3): 559-578.

Hennl, A and Kaiser, A (2008) Ticket-balancing in mixed-member proportional systems. Comparing sub-national elections in Germany. Electoral Studies 27(2): 321-336.

Krook ML (2010) Quotas for women in politics: Gender and candidate selection reform worldwide. Oxford: Oxford University Press.

Meriläinen J and Tukiainen J (2018) Rank effects in political promotions. Public Choice 177(12): $87-109$. 
Put GJ and Maddens B (2013) The selection of candidates for eligible positions on PR lists: The Belgian/Flemish federal elections 1999-2010. Journal of Elections, Public Opinion and Parties 23(1): 49-65.

Shugart MS (2005) Comparative electoral systems research: The maturation of a field and new challenges ahead. In: Gallagher M and Mitchell P (eds) The Politics of Electoral Systems. Oxford: Oxford University Press, pp. 25-56.

Shugart MS, Valdini ME and Suominen K (2005) Looking for locals: Voter information demands and personal vote-earning attributes of legislators under proportional representation. American Journal of Political Science 49(2): 437-449.

Stockemer D and Sundström A (2018) Age representation in parliaments: Can institutions pave the way for the young? European Political Science Review, published online.

Stoffel MF and Sieberer U (2018) Measuring re-election prospects across electoral systems: a general approach applied to Germany. West European Politics 41(5): 1191-1207.

Van Erkel PF (2017) Preferential votes: Explaining individual electoral success in intra-party competition. PhD Thesis, University of Antwerp, Belgium. 


\section{Acknowledgements}

The authors thank the three anonymous reviewers for their comments and suggestions. GertJan Put thanks Academische Stichting Leuven for their financial support. An earlier version of this article has been presented at the ECPR General Conference in Hamburg (2018).

\section{Author Biographies}

Gert-Jan Put is Senior Researcher at KU Leuven (VIVES). His research focuses on candidate selection and intra-party competition, and has been published in Political Behavior, Politics and Electoral Studies.

Jef Smulders is a Research Fellow at KU Leuven (PGI). His research focuses on political finance and campaign spending, and has been published in International Political Science Review, Government and Opposition and Local Government Studies.

Bart Maddens is a professor of political science at KU Leuven (PGI). His research interests include political finance, elections and multi-level systems. His work has been published in West European Politics, Party Politics and Electoral Studies. 